\title{
EROSÃO COSTEIRA E RISCOS ASSOCIADOS AO USO BALNEAR E RECREATIVO DA PRAIA DO ICARAÍ, CAUCAIA, CEARÁ, BRASIL
}

\author{
Érica Nádia Costa Sousa ${ }^{(a)}$, Davis Pereira de Paula ${ }^{(b)}$ \\ (a) Centro de Ciências e Tecnologia, Universidade Estadual do Ceará, ericanadiacs@gmail.com \\ (b) Centro de Ciências e Tecnologia, Universidade Estadual do Ceará, PROPGEO/UECE, MAG/UVA \\ davis.paula@uece.br
}

\section{Eixo: DINÂMICA E GESTÃO DE ZONAS COSTEIRAS}

\begin{abstract}
Resumo
Área comum do uso de todos, a zona litorânea traz para o contexto citadino a potencialidade para a realizações de atividades de lazer e recreação. Por sua grande atratividade diária e sua natureza tão comum, o ambiente praial tende a encobrir alguns fatores que podem oferecer riscos aos seus usuários. A Praia do Icaraí, ambiente que nos últimos anos tem passado por grandes mudanças paisagísticas, induzidas pela erosão costeira é objeto desse estudo, que visa identificar os riscos relacionados ao uso do ambiente praial por banhistas e não banhistas. Nessa praia, os riscos são naturais e antrópicos e estão associados, sobretudo, ao forte processo de erosão costeira que potencializa a construção de obras de proteção, que por si só, configuram um elemento de risco ao usuário.
\end{abstract}

Palavras chave: erosão costeira; mudanças paisagísticas; riscos permanentes e efêmeros.

\section{Introdução}

O ambiente litorâneo, já no final do final do século XX, transformou-se substancialmente quanto ao seu aproveitamento em diversas escalas, do setor de lazer ao industrial. Nesse contexto, houve uma crescente geração de fluxos de todas as ordens para o aproveitamento dos serviços adquiridos dessa zona tão importante atualmente. Esse espaço traz para o cotidiano das cidades costeiras uma enorme potencialidade para a realização de atividades ligadas ao lazer, o banho de mar, a prática de esportes e, até mesmo, a contemplação paisagística, dado o conjunto singular de belezas desse geoambiente.

A intensa procura do ambiente praial para o desenvolvimento de diversas atividades humanas traz alguns riscos aos usuários da praia (banhistas e não banhistas), seja este associado ao banho de mar em águas poluídas ou até mesmo resultante de acidentes com lesão corporal. A praia, naturalmente, por ser um ambiente de intensa dinâmica, pode encobrir elementos que podem oferecer riscos aos seus usuários, sendo, por vezes, subestimados os perigos relativos ao uso do mar.

O risco é a percepção de um indivíduo ou grupo de indivíduos da probabilidade de ocorrência de um evento potencialmente perigoso e causador de danos, ou seja, o risco é a percepção do perigo. Este, por 


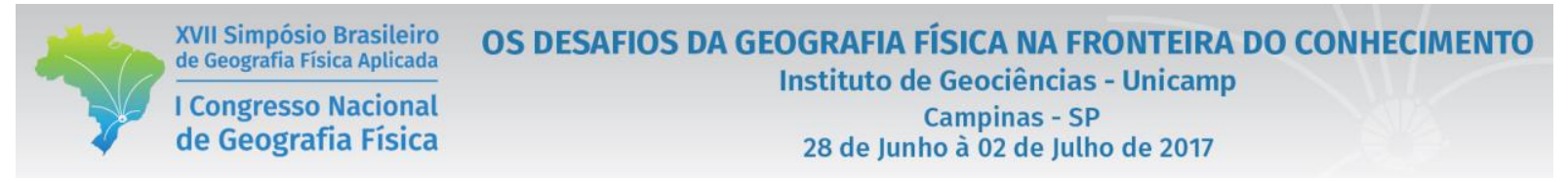

sua vez, tem relação com a possibilidade ou a própria ocorrência de um evento causador de prejuízo (ALMEIDA, 2011, p. 7). Deste modo, o risco de um caminhar nas areias da praia ou um mergulho no mar são relativizados a partir da probabilidade de um acidente.

Logo, o objetivo deste estudo está em identificar e avaliar o risco ao banho de mar em uma praia com profundas transformações antrópicas induzidas, especialmente, pelo desenvolvimento de uma zona de veraneio e a intensificação do processo erosivo na Praia do Icaraí em Caucaia.

\section{2. Área de estudo}

A Praia do Icaraí localiza-se no domínio leste do litoral do município de Caucaia, integrante da Região Metropolitana de Fortaleza - RMF, no estado do Ceará. É caracterizada por uma costa aberta, com dunas antropizada, com agitação marítima mediamente severa e a incidência frequente de afloramentos de rochas de praia, paralelamente à linha de costa (PAULA, 2016).

É um trecho costeiro de pouco mais de $3,5 \mathrm{~km}$, caracterizado por uma linha de costa fortemente antropizada e com um dos mais expressivos focos de erosão no litoral do Ceará que já resultaram em perda de faixa útil de praia, bem como, danos ao patrimônio edificado (PAULA et al. 2016, p. 3). Sendo o trecho costeiro do Ceará, de acordo Paula (2015), que apresenta a maior quantidade de obras costeiras de proteção, ficando atrás apenas de Fortaleza.

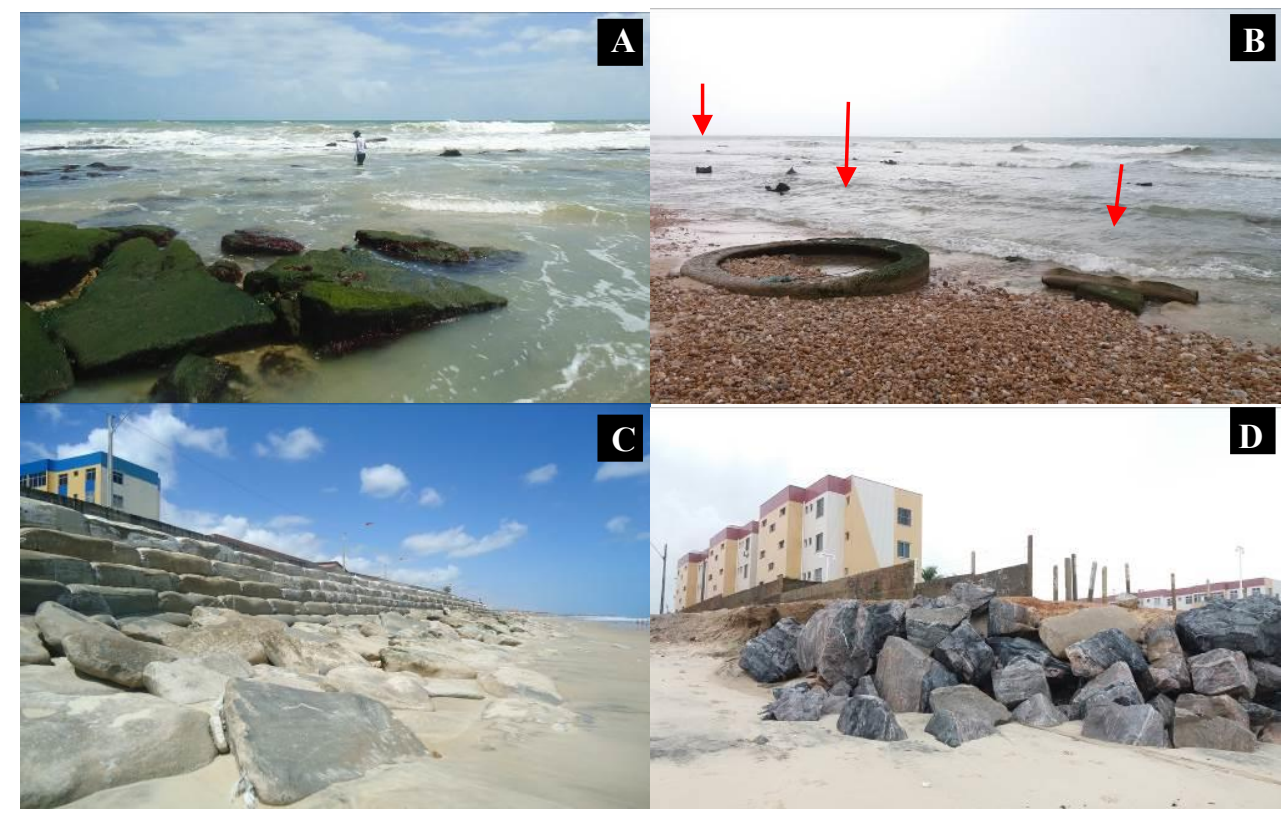

Figura 1 - Na imagem A observa-se o afloramento das rochas de praia, que acompanha paralelamente boa parte da praia; Na imagem B as setas indicam restos de construção civil dispersas na faixa de praia; As imagens C e D são as obras de proteção costeira contidas na orla, o dissipador de energia tipo Bagwall (C) e o Enrrocamento de pedras (D) 


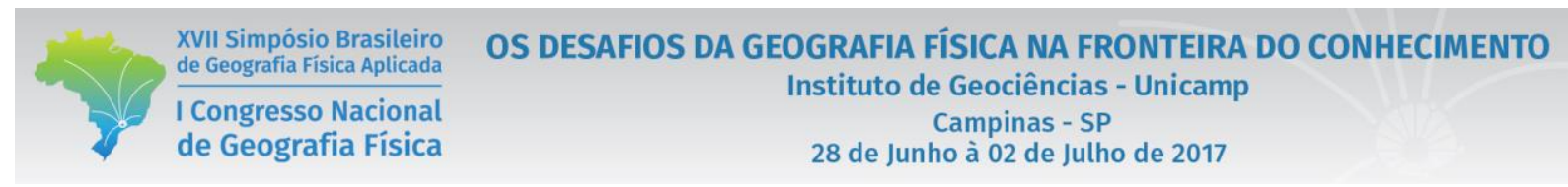

Esse trecho litorâneo apresenta atualmente intensas mudanças paisagísticas, resultado de acumulações de problemas relacionados a erosão costeira ao longo das últimas duas décadas, que deixam alguns testemunhos (e. g.restos de construção) ao longo da faixa praial.

Do ponto de vista recreacional, a Praia do Icaraí é utilizada pela população local e dos municípios vizinhos para práticas de esportes náuticos, pesca, banhos de mar e passeios junto à orla. Nesse contexto, tais problemas observados na praia tendem a impactar na sua qualidade ambiental, bem como oferecer riscos para aqueles que se utilizam do ambiente para prática de alguma atividade, como é o caso do Banho de mar.

\section{Metodologia}

Para a efetivação da proposta de estudo, primeiramente, foi elaborada uma classificação dos tipos de riscos de acordo com a sua origem: os naturais e os antrópicos. O primeiro corresponde aqueles em que o risco tem origem na própria dinâmica do ambiente, como é o caso das feições morfológicas da praia (e.g. cavas e bancos arenosos). O segundo são aqueles decorrentes da exposição dos usuários as estruturas humanas, sejam elas fixas, como é o caso das obras de proteção, ou efêmeras, como no caso dos restos de construções (e.g. ferros, concretos, rochas) provenientes da erosão costeira que ficam espalhados pela face de praia, dos quais são cobertos ou descobertos pelas areias da praia a depender da agitação marítima.

Ao considerar o caráter de exposição aos riscos, estes podem ser permanentes, que não mudam de lugar e uma vez conhecidos podem ser facilmente evitados, e temporários, os quais estão submetidos à dinâmica da praia, como, por exemplo, os restos de construção que dependendo da sua dimensão podem sofrer deslocamentos ao longo do trecho costeiro estudado (Quadro 1).

Quadro 1 - Classificação dos tipos de riscos associados ao banho de mar na Praia do Icaraí

\begin{tabular}{|c|l|l|}
\hline RISCOS & \multicolumn{1}{|c|}{ VARIÁVEIS } & EXPOSIÇÃO \\
\hline \multirow{2}{*}{ Naturais } & Beach Rocks & Permanente \\
\cline { 2 - 3 } & Valas/cavas & Temporário \\
\hline \multirow{3}{*}{ Antrópicos } & $\begin{array}{l}\text { Restos de construção } \\
\text { (Concretos de antigas casas, barras de ferro, etc.) }\end{array}$ & $\begin{array}{l}\text { Temporário/ } \\
\text { Permanente }\end{array}$ \\
\cline { 2 - 3 } & $\begin{array}{l}\text { Obras de proteção costeira } \\
\text { (Bagwall, Enrrocamentos de pedras) }\end{array}$ & Permanente \\
\hline
\end{tabular}

Em etapa seguinte, através do reconhecimento em campo foram obtidas as coordenadas da disposição espacial dos tipos de riscos de acordo com a classificação da tabela 1. Esse procedimento ocorreu em maré baixa e foi realizado com auxílio de um GPS portátil. Posteriormente, já na etapa de mapeamento, as coordenadas foram inseridas no software livre QGIS e espacializadas sobre uma imagem de satélite obtida 


\section{OS DESAFIOS DA GEOGRAFIA FÍSICA NA FRONTEIRA DO CONHECIMENTO \\ Instituto de Geociências - Unicamp \\ Campinas - SP \\ 28 de Junho à 02 de Julho de 2017}

do Google Earth do ano de 2016. O mapa gerado está no sistema de projeção Universal Transversa de Mercator - UTM, datum SIRGAS 2000, zona 24 Sul.

\section{Resultados e discussões}

$\mathrm{Na}$ espacialização dos tipos de riscos, tanto naturais como antrópico, passiveis de mapeamento na faixa de praia encontram-se de forma generalizada dispersos em todo o trecho, como observado na Figura 2.

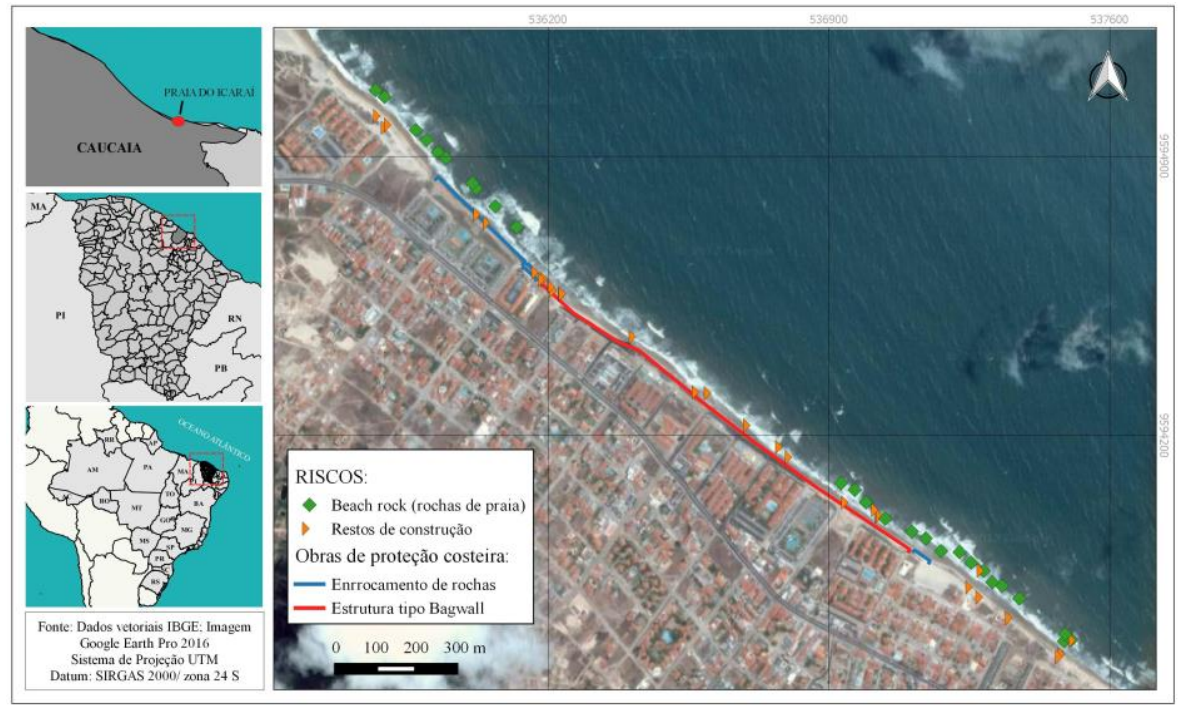

Figura 2 - Mapa dos riscos associados ao banho de mar na praia do Icaraí, localizada município de Caucaia - CE

Os riscos naturais permanentes, em sua maioria, estão diretamente associados às rochas de praia, que estão dispostos de forma paralela a linha de costa, no contato do estirâncio com a ante-praia, e podem ser visualizados total ou parcialmente em período de maré baixa. Isso se não estiverem cobertos por areias, o que impede sua visualização pelos usuários da praia.

Outro risco eminente em ambientes praias é a presença de cavas na praia submersa, esse tipo de risco não é mapeável, pois depende bastante da dinâmica costeira local e da morfologia da praia. Por serem características naturais do ambiente, esse tipo de risco tende a ser subestimado pelos banhistas, principalmente em maré cheia quando ficam totalmente recobertos pelo mar.

Na faixa de praia do Icaraí é comum encontrar restos de construções que são advindos da erosão dos equipamentos urbanos. No mapeamento foram identificados os seguintes elementos construtivos tijolos, barras de ferro, telhas e concreto. Esses são elementos que trazem um elevado grau de risco ao usuário da praia, pois podem provocar lesão corporal com danos diversos. 


\section{OS DESAFIOS DA GEOGRAFIA FÍSICA NA FRONTEIRA DO CONHECIMENTO \\ Instituto de Geociências - Unicamp \\ Campinas - SP \\ 28 de Junho à 02 de Julho de 2017}

Os riscos antrópicos quanto ao seu caráter de exposição foram considerados tanto permanentes, para os testemunhos de tamanhos mais expressivos que dificilmente serão realocados, quanto temporários, para os de dimensões menores, uma vez que estão sujeitos a transporte pela força das ondas, ou mesmo serem recobertos por sedimentos de acordo com a dinâmica da praia. Os mais consideráveis em dimensão e extensão são as obras de proteção costeira que recobrem mais da metade da praia, a exemplo do Bagwall que ocupa uma extensão de 1,5 km, e foi construido em 2011.

Esse tipo de estrutura rígida traz um risco ao usuário da praia em todas as fases de maré, pois o acesso à praia é feito por sobre a estrutura de concreto, que conta com 11 degraus de quase $50 \mathrm{~cm}$ de altura, o que dificulta bastante a descida do usuária até a areia da praia, pondendo nesse transcorrer sofre algum escorregamento nos degraus. Além disso, na preamar, a faixa de areia fica completamente coberta pela maré e as ondas arrebentam diretamente na estrutura, o que torna o banho de mar e a prática de esportes náuticos uma atividade perigosa. Portanto, é possível inferir, de forma geral, que os riscos aos usuários da praia tendem a aumentar sob a influência de eventos naturais como a subida da maré e os eventos de ressacas do mar, pois restringem o campo de visão dos elementos naturais e antrópicos, favorecendo a ocorrência de acidentes.

\section{Considerações Finais}

Os resultados indicam que as mudanças paisagísticas induzidas pelo processo de erosão costeira na Praia do Icaraí, nos últimos anos, têm provocado, sobretudo, danos materiais que incidem diretamente nos riscos aos usuários da praia. O avanço do mar no Icaraí é denunciado pelos testemunhos de restos de obras espalhados pela face de praia, e agora oferecem riscos para a população que frequenta a praia. Associado a isso, os riscos naturais estão presentes nessa praia, especialmente, no que concerne a presença de rochas de praia. Desse modo, o uso recreacional dessa praia torna-se uma atividade de risco ao banhista e não banhista.

\section{REFERÊNCIAS}

ALMEIDA, Lutiane Queiroz de. Por uma ciência dos riscos e vulnerabilidades na geografia. Mercator-Revista de Geografia da UFC, v. 10, n. 23, p. 83-99, 2011.

PAULA, Davis Pereira de. Erosão costeira e estrtuturas de proteção no litoral da Região Metropolitana de Fortaleza (Ceará, Brasil): um contributo para artificialização do litoral. Rede: Revista Eletrônica do Prodema, v. 9, p. 73-86, 2015. 


$\begin{aligned} & \text { XVII Simpósio Brasileiro } \\ & \text { de Geografia Fisica Aplicada }\end{aligned}$
$\begin{aligned} & \text { I Congresso Nacional } \\ & \text { de Geografia Física }\end{aligned}$

PAULA, Davis Pereira; BENDÔ, Antônio Raylton Rodrigues; LIMA, Ismael Furtado Pereira; ALVES, José Wilker Oliveira. Mudanças de curto prazo no balanço sedimentar da Praia do Icaraí (Caucaia, Ceará) durante uma ressaca do mar. Scientia Plena, v. 12, p. 1-12, 2016. 